\title{
VIVENDO SOBRE ESCOMBROS: QUALIDADE DE VIDA NO HAITI PÓS-TERREMOTO
}

LIVING ON THE DEBRIS: QUALITY OF LIFE IN HAITI AFTER EARTHQUAKE

Recibido: 22 de Noviembre del 2011 | Aceptado: 22 de Noviembre del 2012

\author{
CHRISTINA SUTTER ${ }_{1}$; ANANDA MELO KING 2 \\ (UNIVERSIDADE DE FORTALEZA, Ceará, Brasil).
}

\begin{abstract}
RESUMO
Este artigo pretende lançar uma reflexão sobre a qualidade de vida no Haiti, após o terremoto, utilizando os domínios apontados pelo instrumento de avaliação da qualidade de vida da Organização Mundial da Saúde, o WHOQOL 100, como norteadores desta análise. A fim de organizar os dados colhidos in loco antes e depois da catástrofe, desdobramos estes domínios nas categorias contempladas pelas perguntas do referido instrumento: saúde e assistência médica; educação e acesso à informação; renda e profissão; segurança; meio ambiente; espaço físico e moradia; lazer e tempo livre; família e rede social; satisfação com a própria vida e perspectiva de vida; espiritualidade e crenças pessoais. Concluímos que um estudo sobre qualidade de vida no país deve considerar as particularidades das regiões e das condições socioeconômicas de sua população, bem como as características culturais, em que a resiliência e a religiosidade permeiam a maneira como enfrentam os reveses da vida. Considerando que o Haiti já se encontrava em uma situação de crise humanitária antes do terremoto, apontamos um possível impacto paradoxal da catástrofe sobre a população, com efeitos ora negativos sobre a segurança e os laços familiares, ora favoráveis sobre as condições de sobrevivência da população mais miserável.
\end{abstract}

PALAVRAS-CHAVE: Haiti, Terremoto, Crise humanitária, Qualidade de vida.

\section{ABSTRACT}

This article analyzes the quality of life in Haiti after the earthquake, based on the domains of the World Health Organization Quality Of Life assessment instrument (WHOQOL 100). In order to organize the data collected on-site before and after the disaster, the domains were categorized according to the groups denominated in the WHOQOL: health and medical care, education and access to information, income and occupation, security, environment, physical space and housing, leisure and free time, family and social network, satisfaction with life and outlook on life, spirituality and personal beliefs. We conclude that a study on quality of life in Haiti should consider the specific features of the region and its socioeconomic conditions, as well as the cultural features of the population, given that resilience and religiosity strongly affect the way people face the setbacks of life. Taking into account that Haiti was already facing a humanitarian crisis before the earthquake, we point out a possible paradoxical impact of the disaster on the population, with negative effects on security and family ties and favorable effects on the survival conditions of the most miserable segment of the population.

KEY WORDS: Haiti, Earthquake, Humanitarian Crisis, Quality of life.

1. Professora titular do curso do Psicologia Universidade de Fortalezae mestra em psicología pela Universidade de Fortaleza, Brasil.

E-mail: tinasut@gmail.com

2. Consultora de projetos sociais e mestra em antropología social e cultural pela Universidade de Strasbourg, França. E-mail: anandamk@gmail.com 
INTRODUÇÃO

Este artigo pretende tecer uma reflexão sobre o impacto do terremoto de 12 de janeiro de 2010 sobre a qualidade de vida da população haitiana considerando que esta já se encontrava em situação de crise humanitária nas últimas décadas. Para isso teceremos uma comparação entre as condições de vida antes e depois da catástrofe. Nossos comentários são baseados em nossa própria permanência no Haiti, entre julho de 2008 e dezembro de 2010. Como voluntárias de uma organização médica internacional atuando em três projetos - um hospital maternidade na capital Porto Príncipe, (cidade com 2,5 milhões de habitantes, cuja metade vive em favelas), um hospital em Léogâne (cidade com 200 mil habitantes e epicentro do terremoto) e uma clínica em Cap Haitien (segunda maior cidade do Haiti, com 260 mil habitantes), durante a epidemia de cólera nos consideramos testemunhas privilegiadas. Também contribuíram para esta análise os depoimentos de haitianos com os quais mantemos contato até 0 presente e os depoimentos sobre os dias após a catástrofe publicados em livros e artigos publicados acerca das consequências do terremoto em diversos níveis.

Para esta reflexão, utilizaremos como referência os aspectos do instrumento de avaliação de qualidade de vida, o World Health Organization Quality of Life, WHOQOL 100, da Organização Mundial da Saúde (WHOQOL Group, 1995). Neste instrumento, a qualidade de vida é definida como a percepção do indivíduo sobre sua posição na vida, no contexto da cultura e do sistema de valores em que vive e em relação aos seus objetivos, expectativas, padrões e preocupações, elaborados a partir de perguntas que avaliam a percepção dos sujeitos com respeito a seis domínios: a) físico, b) psicológico, c) da independência, d) das relações sociais, e) do meio ambiente e f) da espiritualidade e crenças pessoais. Embora o instrumento não tenha sido aplicado à população haitiana, consideramos adequado tomá-lo como referência para a apresentação de nossas observações sobre a vida no Haiti, já que as dimensões que avalia são consideradas definidoras da qualidade de vida pela instituição que é a representante oficial da saúde do homem no mundo.

Certamente nossa perspectiva pode não corresponder a dados empíricos eventualmente colhidos por pesquisa através deste instrumento. Igualmente, desconhecemos a existência de pesquisas sobre qualidade de vida no Haiti que poderiam responder muitas de nossas perguntas. Entretanto, nossa intenção ao utilizar suas dimensões foi, sobretudo, organizar os dados que dispomos e apresentá-los dentro de um parâmetro que facilite a compreensão de nossos leitores para que possam, eles mesmos, avaliar as condições de vida deste povo, que são precárias em todos os sentidos, e suscitar reflexões sobre o impacto de uma catástrofe natural sobre um contexto social já catastrófico. Consideramos que uma discussão, ainda que teórica, sobre 0 contexto haitiano antes e depois do terremoto é de particular interesse para os profissionais de saúde mental, seja na área humanitária, seja na área da psicologia das emergências e desastres.

\section{Crise humanitária, tragédia e qualidade de vida}

The earthquake changed my way of seeing and understanding things and marked me indelibly. Nothing surprises me now. Dubique Kobel

Para aqueles acostumados a socorrer países atingidos por desastres naturais, 0 Haiti pareceu um desafio intransponível, conforme o relato de três cirurgiões, citado por P.Farmer (2011): "We were unprepared for what we saw in Haiti - the vast amount of human devastation, the complete lack of medical infrastructure, the lack of support from the Haitian medical community, the lack of organization on the ground" (p.71). 
Conquanto a dificuldade em atender prontamente as necessidades da população fosse também reflexo da falta de coordenação e de preparo da comunidade internacional para lidar com desastres em tais condições (Swchartz, 2011; Thomaz, 2011; Trevors \& Saier Jr., 2010), sabe-se que nenhum desastre é totalmente natural.

Embora o Haiti esteja situado em uma região geograficamente vulnerável, isto não é suficiente para explicar a dimensão da catástrofe ${ }^{1}$. Como pergunta $P$. Farmer (2011): "What made Haiti peculiarly vulnerable to the quake, as it was vulnerable to the storms of 2004 and 2008?" (p.117). Conforme Pérez-Sales (2003) se definirmos vulnerabilidade como a predisposição de uma dada comunidade para sofrer graves danos em consequência de um desastre, sabe-se que a pobreza está na raiz de muitas situações de vulnerabilidade, embora não de todas. Por sua vez, o desastre aumenta a vulnerabilidade de modo que esta precisa ser considerada não como um fator estático, mas dinâmico. Se o terremoto provocou um retrocesso no desenvolvimento do país em dez anos (Pan American Health Organization - PAHO, 2011), já havia uma catástrofe econômica, social, ambiental e humanitária no Haiti antes do terremoto. Por onde recomeçar e como quebrar a espiral de vulnerabilidade, quando não há recursos?

Esta pergunta é, contudo, antecedida por outra: Como algo que já é suficientemente ruim, para aqueles que são destituídos de tudo, pode deteriorar? Por mais que a condição de desabrigado seja angustiante, o quanto viver em um acampamento sobre um campo de golfe é pior do que viver em uma favela imunda? Embora os dias que sucederam o sismo tenham sido intoleráveis

1 Estima-se que 25 mil prédios não residenciais e pelo menos 225 mil casas (entre barracos e casas sólidas de alvenaria) colapsaram, deixando um total de $220 \mathrm{mil}$ mortos e 300 mil pessoas gravemente feridas (P. Farmer, 2011). Em Leogâne, epicentro do terremoto, $80 \%$ da cidade foi destruída (Health response to the earthquake, 2011).
(Kobel, 2011), muitos encontraram depois, nos acampamentos de desabrigados, os serviços básicos negados a eles durante décadas (Montas-Dominique, 2011). Portanto, o que significa qualidade de vida nestas condições? De fato, se estamos diante de uma população que já vivia no limite do humano (Sutter, 2010) que critérios utilizar para compreender o impacto de uma catástrofe sobre a qualidade de vida?

$\mathrm{Na}$ época do terremoto, a situação social e econômica do Haiti já vinha se deteriorando há décadas. Considerado 0 país mais pobre do hemisfério ocidental 0 Haiti é o país dos extremos no pior dos sentidos: está entre os países do mundo com maior Índice de Insegurança Humana ${ }^{2}$ e entre os países com menor Índice de Desenvolvimento Humano. $80 \%$ da população vivem em condições de pobreza degradante e sem emprego formal ${ }^{3}$. Com uma renda per capita anual de US\$ 560 , mais da metade da população sobrevive com menos de um dólar por dia. Do ponto de vista da saúde, os índices também refletem o enorme abandono da população: $75 \%$ das crianças não são vacinadas e a mortalidade infantil é de 62,33 por 1.000 nascimentos vivos. A expectativa de vida, em 2009, era de 61 anos.

Pensar em qualidade de vida em um contexto dessa natureza é um desafio. Mais ainda se levarmos em conta as características do povo haitiano, que tem longamente resistido a condições desumanas de vida. Logo após o terremoto nos deparamos com uma população gravemente atingida, física e psicologicamente, com conflitos irrompendo a todo o momento (Kobel, 2011), mas também capaz de grande solidariedade

\footnotetext{
20 Índice de Insegurança Humana contempla a expansão do conceito tradicional de segurança para incluir as assim chamadas ameaças não convencionais, tais como: escassez de recursos, crescimento rápido da população, violação de direitos humanos, surto de doenças infecciosas, degradação do solo, poluição da água, e assim por diante (Lonergan, Gustavson \& Carter, 2009).
}

3 Dados do Index Mundi (2011) 
(Dandicat, 2011; Laferrière, 2011) e capacidade de auto-organização pacífica (Thomaz, 2010). Embora a solidariedade entre as vítimas de desastres não seja prerrogativa do Haiti (PAHO, 1999), não se pode desconsiderar a resistência dessa população, qualidade de caráter aparentemente forjada pela cultura. Igualmente, a forte religiosidade do povo haitiano parece contribuir para essa resistência. Diante do exposto, podemos de antemão antecipar que se a percepção sobre qualidade de vida pós-desastre é certamente determinada pelas prévias condições de vida e pelas características culturais da população, no caso do Haiti ambas as condições parecem ser de fato mais que relevantes, considerando que esta população tem longamente sobrevivido em condições extremas.

O cenário: antes e depois do terremoto

Le confort n'est pas la seule mesure du monde. Dany Laferrière

Considerando este contexto e segundo nossa experiência in loco, propomos uma descrição das condições de vida no Haiti, antes e depois do terremoto, para a avaliação da qualidade de vida conforme as dimensões consideradas relevantes pela OMS constituintes de seu instrumento WHOQOL 100. Para tanto, e a título de organização, separamos algumas categorias contempladas nas perguntas do referido instrumento como norteadoras de nossa análise descrevendo o cenário antes e depois do terremoto: saúde e assistência médica; educação e acesso à informação; renda e profissão; segurança; meio ambiente; espaço físico e moradia; lazer e tempo livre; família e rede social; satisfação com a própria vida e perspectiva de vida; espiritualidade e crenças pessoais. Estas categorias serão apresentadas em um quadro resumo no final do artigo.

\section{Saúde e assistência médica}

Com um sistema deficitário de saúde pública (infraestrutura precária, não gratuidade dos serviços, greves constantes e falta de material hospitalar), o acesso aos cuidados médicos era extremamente limitado. Os mais pobres não podiam pagar as taxas que as clínicas e hospitais solicitavam para consultas, testes laboratoriais, exames e medicamentos. Em pesquisa realizada no Haiti, $67 \%$ da população não tinha acesso ao sistema de saúde e $57 \%$ fazia uso de cuidados alternativos (Médecins Sans Frontières MSF, 2008). Sem a presença de organizações médicas humanitárias e religiosas, permitindo acesso gratuito à saúde, boa parte das necessidades da população não seria atendida. No caso das gestantes, metade dos partos era realizada por parteiras tradicionais, fosse devido à dificuldade de pagar um transporte para ir ao hospital, fosse devido à falta de informação. Estes fatos, associados à ausência de atendimento pré-natal, fazia do Haiti o país do Ocidente com o maior índice de mortalidade materna: 680 por 100.000 nascimentos (MSF Briefing Paper, 2008). Ao longo das últimas décadas três mil organizações não governamentais se instalaram no Haiti para socorrer a população a ponto de o país ser conhecido como a "República das ONGs", por concentrar o maior número de ONGs per capita no mundo (United States Institute of Peace, 2009).

No Haiti, muitas doenças são a consequência da pobreza extrema em que vive o país: tuberculose, anemia severa devido à desnutrição crônica, febre tifóide, malária e poliomielite são comuns entre sua população (P.Farmer, 2005). Devido à desconfiança na medicina oficial, práticas de cura tradicionais são aderidas pela população mais carente, levando muitas vezes ao agravamento do estado de saúde, como era o caso de pacientes com préeclampsia. 
Devido ao terremoto, $60 \%$ das estruturas médicas no Haiti foram destruídas (MSF, 2010). Em Léogâne, a carência era total. Embora diversas equipes de emergência tenham se instalado no local para atender a população, a falta de infraestrutura prévia refletia-se na dificuldade de coordenar as ações entre as equipes voluntárias (Schwartz, 2011). Em Porto Príncipe, a população teve que ser atendida em áreas improvisadas a céu aberto. Mas o número de feridos e mortos estava muito além da capacidade de resposta imediata e adequada, considerando o contexto anterior de inúmeras carências na saúde. Várias pessoas, com fraturas graves, ficaram dias esperando socorro nas ruas e amputações foram feitas sem anestesia ( $P$. Farmer, 2011).

Nove meses após o terremoto uma epidemia de cólera espalhou-se pelo país, levando a quatro mil óbitos nas primeiras semanas e mais de 400 mil pessoas contaminadas até 0 presente. Embora a base nepalesa da Minustah (Mission des Nations Unies pour la Stabilisation d'Haiti) tenha sido responsabilizada pela contaminação, a insalubridade das comunidades rurais e urbanas e o escasso acesso à água potável: foram fatores eficazes para que a cólera se espalhasse rapidamente (Detrás de la epidemia, 2010). 0 ambiente físico também foi atingido. Em Cap Haïtien, onde a epidemia alastrou-se rapidamente, alguns corpos permaneceram estendidos nos acostamentos das ruas próximas a grandes favelas. Devido à falta de informação, uma onda de desespero acometeu a população e diversas famílias abandonaram os seus. Neste sentido, a promoção da saúde foi crucial para sensibilizar e mobilizar as populações atingidas, sobretudo através dos agentes comunitários de saúde.

A gravidade da epidemia reconduziu os investimentos de várias ONGs, reduzindo temporariamente 0 trabalho aplicado em outras áreas sociais ou da saúde, como 0 atendimento a mulheres vítimas de violência sexual.

\section{Educação e acesso à informação}

O analfabetismo alcança o índice de $47 \%$ no Haiti (Index Mundi, 2011). As escolas públicas não são totalmente gratuitas e para garantir a oportunidade de estudar meninas dos bairros mais pobres trocam favores sexuais pelo pagamento da mensalidade escolar. Embora existam cursos profissionalizantes e universitários, somente uma minoria tem acesso a estes cursos, de modo que a desigualdade social é reforçada pela exclusão da grande maioria à educação. Os que possuem recursos costumam estudar em universidades fora do país e muitos aproveitam para emigrar definitivamente.

Como as escolas colapsaram com 0 terremoto, algumas foram edificadas em madeira perto dos acampamentos, bem como foram erguidas instalações provisórias para os cursos universitários, porquanto a Universidade do Estado do Haiti também tombou. Muitas crianças, entretanto, permanecem sem estudar e entre aquelas que voltaram aos estudos existe uma alta incidência de problemas de aprendizagem como sintoma do estado emocional destas crianças (D.M. Jean-Charles, comunicação pessoal, Outubro de 2011).

As rádios comunitárias eram consideradas importantes veículos de comunicação no cotidiano dos haitianos, tanto nas zonas rurais quanto urbanas. Diversos cultos religiosos eram também transmitidos através das estações de rádio. A comunicação via radio reflete um sentimento de pertencimento comunitário e a troca de informações poderia ser mencionada aqui como um indicativo de qualidade de vida. Igualmente, a telefonia celular era bastante acessível. Todavia, a totalidade da população mais pobre não possuia televisão, como nenhum outro eletrodoméstico. Em Porto Príncipe existiam 
várias lan houses, embora a qualidade do acesso à internet fosse precária.

Depois do terremoto, o radio continuou sendo o principal veículo de comunicação no Haiti. Apesar de as estações de radio terem sido atingidas, estas foram sendo revitalizadas aos poucos e seis meses depois já havia várias estações em funcionamento.

\section{Renda e profissão}

Com a quase totalidade da população desempregada, 0 dinheiro sempre foi insuficiente para satisfazer as necessidades básicas como alimentação e transporte. $\mathrm{Na}$ maternidade, muitas mulheres chegavam sem nenhuma roupa para o bebê que ia nascer. Como alternativa ao desemprego, 0 trabalho informal era de fato uma fonte de renda. $\mathrm{Na}$ capital, as pessoas sobreviviam vendendo artigos diversos nas ruas (geralmente roupas doadas de segunda mão), ou da ajuda financeira de parentes que viviam no Canadá e EUA (L'émigration est la meilleure, 2010). Na verdade, devido a instabilidade política e ao frágil mercado de trabalho, milhares de haitianos já viviam fora do país, antes do terremoto. Como parte das estratégias de sobrevivência, há relatos de que algumas pessoas se deixavam contaminar com HIV para serem aceitas nos programas de ajuda financeira e alimentar de ONGs locais. Sequestros também podiam ser orquestrados por uma pessoa da própria família, quando chegavam remessas de dinheiro enviadas pelos parentes.

Por outro lado, a baixa oferta de mercado favorecia a violação de direitos trabalhistas. Neste sentido, as mulheres eram as mais afetadas, não obtendo, por exemplo, 0 cumprimento da licença maternidade. Conseguir um emprego nas ONGs internacionais era garantia de ter os seus direitos respeitados e, por isso, os cargos nestas organizações eram extremamente disputados. Porém, para aqueles que conseguiam uma formação profissional mais qualificada, como curso superior e técnico, o diploma não representava uma possibilidade de emprego de modo que havia pessoas que nunca conseguiram um trabalho na vida.

O trabalho informal através de pequenos comércios improvisados na rua foi retomado assim que possível, dias depois do sismo. A enorme afluência de donativos para ajudar a população sinistrada logo se converteu em produtos comercializados nas ruas. Como muitas pequenas empresas faliram em seguida ao terremoto, 0 desemprego aumentou. Entretanto, 0 programa internacional Cash-For-Work ${ }^{4}$ tem oferecido trabalhos diários para a população mais pobre, como limpar os escombros do terremoto, permitindo uma renda mínima para a sobrevivência. Mas como se trata de trabalhos temporários, conforme o próprio objetivo desta iniciativa, não chegam a mudar realmente 0 cenário econômico. Ademais a eficácia deste tipo de programa é duvidosa devido à denúncia de corrupção presente na distribuição das vagas (Argent contre travail, 2011).

Contudo, se é certo que o aumento do número de organizações internacionais após 0 terremoto proporcionou, para diversos haitianos, emprego e salário fixo, mesmo que temporariamente, trouxe também as conseqüências já conhecidas das conjunturas humanitárias, como 0 aumento da inflação local de modo que uma parcela da população beneficia-se enquanto outra é prejudicada.

\section{Segurança}

Com um passado marcado por insegurança política e conflitos armados, os haitianos

4 Cash for Work (CWF) é um programa pós- desastres que utiliza diversas instituições governamentais e não governamentais para oferecer trabalho e fazer circular 0 dinheiro, movimentando a economia do país atingido. No Haiti o programa foi iniciado pela ONG Oxfam America. 
vêm lidando, há décadas, com as consequências da violência sobre a qualidade de vida. Em uma pesquisa realizada em dois bairros populares de Porto Príncipe (Ponsar, Ford, Van Herp, Mancini \& Bachyi, 2009), os autores concluem que as conseqüências humanitárias da violência urbana são similares às causadas por conflitos armados: pessoas são mortas, feridas ou têm que se mudar do bairro; a infraestrutura é danificada ou destruída; 0 acesso à saúde é restrito. Embora pesquisas relatassem que o nível de segurança havia melhorado, nos últimos anos, no bairro popular de Bel Air (Fernandes \& Nascimento, 2007), os sequestros, estupros e assaltos no meio da noite eram frequentes. De fato, não havia segurança em Porto Príncipe a exemplo das cidades onde a exclusão social está presente. A carência de iluminação pública contribuía para a insegurança da população. Até meados de 2008, havia uma média de 30 sequestros por mês (L'insécurité à Haïti, 2008) o que deixava a população da capital em estado de alerta. Por outro lado, as incursões dos soldados das forças de paz nas favelas, embora fizessem parte do cenário quotidiano, também eram vivenciadas como situações de perigo pelo risco de tiroteio que acarretavam.

No concernente à violência sexual, as mulheres eram as mais vulneráveis devido à frequência e à gravidade dos estupros (Médecins du Monde, 2005). Com uma prevalência de 1.698 de vítimas de estupro por 100.000 habitantes ao ano (Luchi, 2010), várias organizações feministas locais e médicas internacionais ofereciam atendimento às vítimas. Para muitos haitianos, o hábito cultural à violência a justifica por si só, tornando o uso da força física autoritária contra as mulheres uma rotina. Na tentativa de modificar este contexto foi criado o Ministério da Condição Feminina como parte das políticas públicas contra a violência de gênero.
0 aumento da insegurança após 12 de janeiro de 2010 era comentado em todas as áreas geográficas atingidas pela catástrofe, em parte devido à fuga de detentos das prisões destruídas. Os criminosos até hoje se aproveitam para se esconder nos acampamentos e a praça Champs de Mars, em frente ao Palácio Nacional, tornou-se uma "terra sem lei". A incidência de roubos também aumentou significativamente em Léogâne, bem como a violência em geral, como resposta ao impacto psicológico que 0 terremoto causou (Melo King, 2010). No entanto, não há registro de aumento do número de atendimentos médicos a vítimas de violência em relação aos dados anteriores (MSF, 2010).

O contexto social, que já constituía um risco para a mulher, ficou ainda mais agressivo. 0 colapso da infraestrutura destruiu a proteção física e social contra a violência sexual. Nos acampamentos, garotas eram sistematicamente violadas, principalmente quando iam ao banheiro à noite, resultando em gravidez forçada (D.B. Farmer, 2011). Por outro lado, como ser mulher no Haiti é uma condição para se sentir em insegurança, agradar os homens, às vezes com favores sexuais, é uma estratégia de proteção à sua integridade física (Melo King, 2010).

A insegurança também atinge a população em outros domínios. Propriedades privadas invadidas pelos desabrigados têm sido exigidas de volta por seus donos provocando uma insegurança permanente naqueles que ocupam os acampamentos devido ao medo de serem desalojados.

\section{Meio ambiente, espaço físico e moradia}

Porto Príncipe é uma cidade barulhenta, devido aos geradores que suprem a deficiência de fornecimento de energia elétrica no país. $O$ ar é poluído seja pelo monóxido de carbono de carros sem manutenção, seja pelos odores pestilentos 
do lixo acumulado nas ruas. Esgotos a céu aberto tornam 0 ar nas favelas irrespirável. Quando se entra nas favelas haitianas compreende-se o significado da expressão 'pobreza abjeta', tanto usada para descrever a miséria do país. A maioria dos barracos não poderia ser chamada de lar, de tão pequenos, escuros e quentes. $O$ entorno é caótico e sujo, com um amontoado de abrigos improvisados com folhas de latão ou de tijolos de cimento sem estruturas de ferro. Mesmo fora das favelas, muitos prédios são edificados sem as normas de segurança levando a desmoronamentos espontâneos, como foi o caso de uma escola em que dezenas de crianças morreram em novembro de 2008 (HaïtiAccident, 2008).

Após o terremoto, diversas famílias da capital e do epicentro do terremoto passaram a viver em abrigos urbanos improvisados e outras acamparam no terreno de suas antigas casas destruídas. As condições de vida nestes locais pioraram com 0 aumento da insegurança e da insalubridade do meio ambiente, acarretadas pelo acumulo de concreto e restos das construções tombadas. A maioria dos prédios públicos não foi reconstruída $\mathrm{e}$ apenas alguns deles foram demolidos $e$ seus escombros retirados. Em Porto Príncipe, favelas como Cité Soleil aumentaram de tamanho com a chegada dos desabrigados, apesar de 500 mil pessoas terem abandonado a cidade (PAHO, 2011).

Entre os 1001 acampamentos, aqueles coordenados por equipes com experiência em deslocamento de populações, oferecem água potável e instalações sanitárias. Nestes, o número de vítimas de cólera foi menor (P. Farmer, 2011). Mas nos abrigos as famílias estavam sujeitas a inúmeras doenças bem como naqueles acampamentos que não satisfaziam as necessidades sanitárias, com uma latrina para cada cem pessoas.
Muitos dos acampamentos foram instalados fora de Porto Príncipe, a fim de esvaziar a cidade, e a população parece resignada a ficar onde está. Porém, esta distancia dificulta a empregabilidade da população. Algumas mini-casas temporárias de madeira com apenas um cômodo, chamadas de T-Shelter, foram construídas. Mas apenas 80 mil famílias foram beneficiadas dentre as milhares que vivem nos acampamentos, privilegiando principalmente os antigos proprietários (Abandonados como perros, 2011). Nestas vilas improvisadas, as famílias ficam esperando pelas prometidas moradias permanentes. Entretanto, algumas pessoas preferem permanecer acampadas porque assim continuam recebendo ajuda das ONGs.

\section{Lazer e tempo livre}

Pode-se falar em lazer e tempo livre para a população desempregada do Haiti? Certamente não nos termos que nos são familiares. Lazer está associado a entretenimento, divertimento, recreação e é caracterizado pela livre escolha. Tempo livre se refere à liberação do tempo dedicado ao trabalho (Aquino \& Martins, 2007). Diante de um tempo improdutivo, não há, de fato, tempo livre. Igualmente, sobreviver nas favelas não é aproveitar a vida (Corten, 2006). É difícil relaxar neste ambiente pouco acolhedor e com a fome nunca plenamente saciada.

As únicas válvulas de escape parecem ser o dominó, para homens desocupados, 0 carnaval e o sexo para um povo de alma musical e sensual. Sendo o Haiti um país caribenho, a música é muito presente na vida da população através do kompas e do zouk, gêneros musicais difundidos no país. Quanto ao sexo, parece permitir algum encontro com o prazer de viver neste país em que a sexualidade está fortemente presente na cultura. Com efeito, no Haiti, o sexo é considerado o antídoto da morte e como parte dos rituais do dia dos mortos, 
existe uma grande festa nacional dançante com músicas de texto lascivo ${ }^{5}$.

Outra paixão nacional é o futebol com torcedores inflamados de grandes times mundiais, entre eles o Brasil e a Argentina, preferidos da população. 0 país parece se dividir ao meio quando estes dois times jogam juntos. É possível ver garotos jogando bola em espaços improvisados nas ladeiras e imagens de craques, como as de Ronaldo e Maradona, pintadas nos tap taps (transportes públicos muito coloridos). Como o final da copa do mundo foi apenas seis meses depois do terremoto, em julho de 2010, diversas ruas, em Porto Príncipe, estavam pintadas com as cores da bandeira do Brasil e bandeirolas enfeitando trechos de avenidas e becos.

Em 2011, a festa de carnaval foi retomada com as pessoas aparentemente se divertindo, como se nada tivesse acontecido. Após o terremoto, algumas danceterias e bares voltaram a funcionar, frequentados por haitianos vindos de uma melhor condição social, e outras se adaptaram ao novo ambiente físico.

\section{Família e rede social}

Com uma esperança de vida baixa, muitos jovens e adultos são órfãos e, às vezes, totalmente sozinhos na vida. Vários perderam praticamente toda a família, devido aos furacões e enchentes, comuns na região. Quando têm ainda um ou outro parente é frequente terem perdido o contato ou não poderem contar com a ajuda deles. Em Porto Príncipe, o lema parece ser cada um por si e a família não tem o sentido de acolhimento e proteção ao qual estamos acostumados. A diferença pode ser notada através da prática comum entre as famílias

5 Uma das festas mais importantes do vodu é a cerimônia em honra do espírito da morte, o Iwa Gédé. Durante a visita aos cemitérios no dia 2 de Novembro, homens possuídos pelo Gédé provocam facilmente o riso. 0 Gédé é um espírito fálico que conta histórias atrevidas, faz gestos obscenos e dança lascivamente, zombando da morte (Hurbon, 1993). haitianas mais pobres de expulsarem de casa a menina adolescente obrigando-a a procurar um homem que a acolha. Também pode ser que a família mande embora a filha durante a gestação ou assim que 0 bebê nasça. Na maternidade, muitas vezes, nos deparamos com jovens que não tinham para onde ir com o seu bebê. Às vezes, um vizinho vinha ao hospital e a acolhia temporariamente. Outras pessoas, sem moradia também, ficavam de casa em casa dependendo da boa vontade alheia. Percebia-se certa solidariedade entre vizinhos e entre membros de uma mesma igreja, porquanto a rede familiar era incerta ou inexistente. Era freqüente a presença de vizinhos acompanhando as vítimas de violência sexual. Igualmente, podia-se perceber a presença de um líder religioso nas decisões tomadas pela família.

O terremoto parece ter tido um duplo efeito sobre as relações: se, por um lado, solidarizou as pessoas em torno da perda mobilizando inclusive parentes vivendo no estrangeiro que mandaram buscar seus familiares -, por outro, fragmentou as famílias mais vulneráveis. Muitas pessoas perderam totalmente 0 contato com parentes e amigos, sem saber se foram mortos, se emigraram ou se voltaram para 0 campo. Até hoje, quase dois anos após 0 sismo, crianças pequenas entre três e seis anos são abandonadas nos hospitais da capital pelos pais, porque estes não têm condições de cuidar delas (D.J. JeanCharles, comunicação pessoal em Outubro de 2011). É difícil encontrar abrigo para essas crianças que se juntam aos órfãos do terremoto.

Nos acampamentos também não é incomum encontrar mulheres com filhos abandonadas por seus maridos. Nesse contexto, conseguir um homem que possa suprir as necessidades de sobrevivência é importante, mesmo que as maltratem. A estratégia do abandono do outro à própria sorte parece, assim, ser comum no Haiti quando não se sabe como garantir a 
sobrevivência. Se o suporte social está relacionado a uma melhor qualidade de vida entre as vítimas de um terremoto (Ke, Liu \& $\mathrm{Li}$, 2000), ou a prevenção de desenvolvimento de transtornos psicológicos (Garcia \& Mardones, 2010) este parece ser um ponto frágil na cultura haitiana.

Contudo, as relações sociais e familiares não se dão exatamente da mesma forma em todas as regiões. Em Léogâne era visível um sentimento de pertencimento familiar que respeitava determinadas regras de conduta ainda presentes no campo. Essa conduta parece estar intimamente ligada à religiosidade, que é transmitida de geração em geração e que favorece também as amizades.

Perspectivas de vida e satisfação com a própria vida

Habitar uma favela é um destino do qual raramente se pode escapar (Corten, 2006), principalmente quando se trata de uma favela no Haiti, onde a vida é vivida em suas mínimas possibilidades. Entre os mais vulneráveis, o nível de satisfação com a própria vida pode ser deduzido pela falta de perspectivas, de emprego, de acesso à escolaridade e à saúde, pela ausência de respeito aos direitos civis e trabalhistas, pela má qualidade da moradia e do entorno ambiental. Igualmente, o fato de o Haiti ser um país miserável localizado em uma ilha caribenha, com a presença massiva de organizações internacionais e com metade de sua população vivendo em países ricos, pode ser fonte de insatisfação, ao considerarmos que a satisfação das necessidades criadas pelo grau de desenvolvimento econômico e social de determinada sociedade é uma referência para a qualidade de vida (Minayo, Hartz \& Buss, 2000). A qualidade de vida também pode ser definida em termos da distância entre expectativas individuais e a realidade (Minayo et al.,2000) e no Haiti, essa distância pode assumir grandes proporções, sobretudo nas áreas urbanas em que a população mais pobre convive com uma distante mini elite.

Depois de 12 de janeiro de 2010, falar sobre perspectiva de vida para uma população com poucas chances de um futuro acolhedor não é simples. Entretanto, muitos haitianos esperam por dias melhores e a esperança está parcialmente depositada nas organizações internacionais. 0 terremoto intensificou também a já conhecida prática de imigração. Muitos aproveitaram a situação de caos e desespero para partirem. Medidas como autorizações provisórias de permanência foram concedidas a todos os haitianos que decidiram ir para a França, apesar da inexistência de uma política que permitisse que os emigrantes trabalhassem no território francês (La France en fait-elle, 2011).

Algumas pessoas aproveitaram 0 terremoto para estabelecerem um novo "lar", fossem movidas pelo desejo de estar sozinhas em tendas novas ou em casais, longe da família de origem. Outras solicitaram tendas que nunca seriam ocupadas, nas conhecidas áreas "fantômes", para receberem mais ajuda das organizações.

Embora para os mais pobres o terremoto provavelmente não represente um abalo radical nas crenças em relação à vida uma ruptura quanto a fé na justiça e na bondade do mundo, como costuma acontecer em situações de desastres (Garcia \& Mardones, 2010) - muitos expressam 0 sentimento de não pertencimento àquele contexto onde tudo foi destruído ou deixou de existir (Melo King, 2010). As pessoas vivem o dia a dia, mas os balizadores parecem faltar, por mais precários que fossem no passado, como as antigas moradias. Muitos não se sentem mais eles mesmos e dizem precisar de ajuda. A psicologia no Haiti, todavia, é uma 
prática estigmatizada ${ }^{6}$. A relação dos haitianos com o sofrimento psíquico não se parece com o nosso hábito de cultivar a angústia e de querer compartilhá-la. Como diz Laferrière (2011, p.161) "en Haiti on se moque brutalement de vos angoisses". Isto se verifica nas crianças que aprendem, desde cedo, a não chorar quando sentem dor (Neves, 2011). Entretanto, pode-se perguntar se o elevado índice de violência doméstica e sexual aponta para uma expressão coletiva da frustração.

Por outro lado, no concernente à unidade do povo haitiano, 0 terremoto também sacudiu a falta de crença deste povo em si mesmo, em suas instituições e em seus políticos. Michèle MontasDominique (2011), designada para ser a porta-voz do povo haitiano na International Donor's Conference em Março de 2010, realizou 156 grupos-focais para capturar as aspirações da população acerca da reconstrução do país. Entre as 1750 pessoas que foram ouvidas, havia forte senso de urgência no sentido de aproveitar a terrível oportunidade dessa catástrofe para finalmente fazer as mudanças tanto esperadas nos últimos trinta anos. Muitos viram o terremoto como um divisor de águas e o começo de um período de reconstrução, no qual a ajuda estrangeira deveria reforçar a soberania e a independência do Haiti. Em termos de perspectiva de vida, para muitos, a tragédia que se abateu sobre o país parece assim ter mobilizado um renovado sentimento de esperança e de solidariedade.

Contudo, quase dois anos depois da catástrofe praticamente nada mudou e a reconstrução do país ainda não aconteceu. Milhares de pessoas continuam nos acampamentos de desabrigados e a ajuda que têm recebido soa mais como paliativa e não, de fato, como (re) construção.

6 A loucura não é considerada uma doença, mas um golpe do destino, de modo que é difícil aceitar o tratamento de uma doença que é negada pela população, como afirma Laferrière (2011): "O único mal-estar reconhecido como um desconforto é uma dor aguda, cuja intensidade não cede depois de três dias" (p. 161). mundo também parece já ter se esquecido do Haiti, embora o país continue sendo 0 celeiro das ONGs. A resiliência característica deste povo e acentuada após o terremoto, se mistura, assim, com certa expectativa de que o mundo possa fazer mais pelo Haiti. No entanto, uma grande parte da população sabe que não verá a chegada deste dia.

\section{Espiritualidade e crenças pessoais}

O haitiano é, em sua maioria, um povo fortemente religioso. A população se divide entre voduisants, católicos e evangélicos, estes em número crescente. Entre os cristãos, a expressão "Si Dieu le veut" é muito repetida, referindo-se tanto a uma fé em Deus de que dias melhores virão, como também um conformismo com a situação, entregando nas mãos de forças superiores a inteligibilidade da vida. A maioria da população do campo e a que vive nas favelas da capital é adepta do Vodu, embora este seja combatido pelos evangélicos e associado ao mal. Mas 0 Vodu é fielmente resguardado como referencia à ancestralidade africana e permite certa apropriação da própria vida através de suas práticas. Podemos afirmar que a religiosidade, seja de que forma ela se expresse, parece representar um fator de resiliência para a população haitiana, associada a certo fatalismo.

A relação com a morte e o luto intensificou-se devido ao grande número de mortos e desaparecidos durante o terremoto o que parece ter tornado a relação com a religião mais necessária. Acompanhar funerais foi, por um período considerável de tempo, parte do quotidiano de caos e sofrimento. A relação do haitiano com a morte é de intensa entrega à vivência da dor: lamentações, gritos e danças parecem exorcizar a perda da pessoa querida.

A destruição de igrejas e templos evangélicos não desmotivou os haitianos a rezarem e a celebrarem em grupo suas 
crenças. Diversas tendas improvisadas foram erguidas nos antigos locais de reza. Se a religião trouxe alívio, no entanto, reforçou o sentimento de culpabilidade do povo haitiano por seus próprios males. Segundo Le Breton (2006), para as pessoas religiosas, a dor pode ser um lembrete constante da fragilidade moral do homem. No Haiti, a dor parece ter tomado uma dimensão ainda maior. Entre uma parcela da população, o terremoto foi interpretado como uma enorme punição divina que se abateu sobre praticamente todo país porquanto todas as pessoas foram afetadas por ele.

\section{CONSIDERAÇÕES FINAIS}

Menm si peyi a kraze li pap mouri ${ }^{7}$

Em um contexto cultural complexo como o do Haiti e com uma desigualdade social tão vertiginosa, um estudo sobre qualidade de vida após uma catástrofe necessita considerar as diferenças entre as regiões e entre as condições de vida dos segmentos da população, bem como o impacto dessas diferenças sobre as concepções de bemestar. A miséria absoluta pode subverter os parâmetros do que seja considerada uma catástrofe ou não, se as consequências desta trouxerem alguma melhora sobre a qualidade de vida. Igualmente, as características culturais e 0 fator religiosidade também precisam ser levados em conta, na medida em que podem outorgar sentidos inabituais ao que é normalmente vivido como trágico.

Podemos antecipar que no concernente à violência contra a mulher, o terremoto teve um efeito catastrófico, bem como sobre 0 sentimento de segurança geral da população, pontos já bastante vulneráveis antes do sismo. Para os totalmente destituídos, manter os laços familiares ficou ainda mais difícil, apesar de a comunidade haitiana, dentro e fora do Haiti, ter se solidarizado em torno desta tragédia. Se 0 terremoto mobilizou uma rede social capaz de fazer frente ao caos dos primeiros dias e socorrer a população, o apoio social, como importante fator psicossocial de enfrentamento a desastres, se fragilizou ainda mais deixando mulheres e crianças entregues à própria sorte. Portanto, se podemos concluir algo a partir destas reflexões, é que o terremoto parece ter tido um impacto paradoxal sobre a qualidade de vida da população.

Não resta dúvida que o país está "pior" do que antes, pois é um país em ruínas. Mas para uma parcela da população dos mais pobres a catástrofe também trouxe ganhos secundários, como acesso a um mínimo de sanitização, assistência, alimentação e algum salário. De certa forma, a catástrofe também reacendeu a esperança de que finalmente o Haiti poderia mudar, renovando a fé na capacidade de autogestão. Esperança que se enfraquece na medida em que o tempo passa e nada acontece. A população parece assim ter ficado suspensa entre o otimismo de uma mudança necessária e urgente e 0 pessimismo das evidencias de se defrontar de modo ainda mais brutal com o abandono e as dificuldades de sempre. Por outro lado, a catástrofe reforçou a desesperança dos que ainda se sentiam leais à pátria mãe, aumentando a fuga para a diáspora redentora. Para os mais pobres, sem acesso a saídas alternativas, a religiosidade e a habitual resistência frente às dificuldades da vida parecem ser as referencias internas que servem para suportar 0 insuportável, embora 0 sofrimento psíquico esteja presente $\mathrm{e}$ externado através do aumento da violência.

Com esta breve análise das condições de vida antes e depois do terremoto de 2010 espera-se mobilizar o interesse em pesquisas que ajudem na compreensão dos fatores apontados nesta discussão de modo a pautar futuras intervenções em saúde mental em contextos similares em que catástrofes naturais e humanitárias se somam. Eventuais pesquisas poderiam 
definir qual estratégia em saúde mental é mais adequada ao discernir os efeitos psicológicos do terremoto sobre a população haitiana, considerando as particularidades de expressão cultural do sofrimento psíquico desta população. Finalmente, pesquisas poderiam elucidar em que medida a longa exposição à miséria humana associada à resiliência, como traço cultural, interfere ou não tanto na percepção das catástrofes quanto na percepção da qualidade de vida.

\section{REFERÊNCIAS}

Abandonados como perros de la calle. (2011). Tierramérica/Haiti Grassroots Watch.

Recuperado da http://www.tierramerica.info/nota.php?lang $=$ esp\&idnews $=4057$.

Aquino, C. A. B. \& Martins, J. C. de O. (2007). Ócio, lazer e tempo livre na sociedade do consumo e do trabalho. Revista Malestar e Subjetividade, 7(2), 479-500.

Argent contre travail : à quel prix? (2011). Haiti Grassroots watch. Recuperado da http://haitigrassrootswatch.squarespace.co m/ayiti-kale-je-kreyl/2011/7/18/argentcontre-travail-a-quel-prix.

Corten, A. (2006). Planète misère: Chroniques de la pauvreté durable. Paris: Éditions Autrement.

Dandicat, E. (2011). The other side of the water. Em Farmer, P., Haiti after the earthquake (pp. 249-258). New York: PublicAffairs.

Detrás de la epidemia de cólera. (2010). Haiti Grassroots watch. Recuperado da http://haitigrassrootswatch.squarespace.co $\mathrm{m} /$ haiti-veedor-espanol/2010/12/26/detrasde-la-epidemia-de-colera.html.

Farmer, D. B. (2011). Mothers and daughters on Haiti. Em Farmer, P., Haiti after the earthquake. (pp. 282-295). New York: PublicAffairs.

Farmer, P. (2005). Pathologies of Power. Health, human rights, and the new war on the

poor. University of California Press.
Farmer, P. (2011). January 12 and the aftermath. Em Farmer, P. Haiti after the earthquake. (pp.54 - 120). New York: PublicAffairs.

Fernandes, R.C. \& Nascimento, M. S. (2007). La violence à Bel Air, Port-au-Prince,

Haiti. Étude sur la victimisation. The International Bank for Reconstruction and

Development /The World Bank.

Garcia, F. E \& Mardone, R. (2010). Prevención de trastorno de estrés postraumático en

supervivientes del terremoto de Chile de febrero de 2010: una propuesta de

intervención narrativa. Terapia Psicológica. Vol. 28, № 1, 85-93

Haïti-Accident: L'effondrement de l'édifice d'une école évangélique provoque un

nouveau drame humain. Alter Presse. Recuperado da http://www.alterpresse.org/spip.php?article 7861.

Hurbon, L. (1993). Les mystères du vaudou. Paris: Gallimard.

Index Mundi (2011). Recuperado da http://www.indexmundi.com/pt/haiti/.

Ke, X.; Liu, C. \& Li, N. (2000). Social support and quality of life: a cross-sectional

study on survivors eight months after the 2008 Wenchuan earthquake. Psychiatriy and Clinical Neurosciences (54), 427 -433.

Kobel, D. (2011). Doctors in tents. Em Farmer, P., Haiti after the earthquake (pp. 316-

319). New York: PublicAffairs.

Laferrière, D. (2011). Tout bouge autour de moi. Paris: Éditions Grasset \& Fasquelle.

L'émigration est la meilleure solution pour les Haïtiens (2010). Slater Fr. Recuperado da http://www.slate.fr/story/17091/lemigrationest-la-meilleure-solution-pour-les-haitiens.

La France en fait-elle assez pour Haïti? (2011). L'Express. Recuperado da http://

www.lexpress.fr/actualite/societe/la-franceen-fait-elle-assez-pour-haiti

Le Breton, D. (2006). Anthropologie de la douleur. Paris: Éditions Métailié.

L' Insecurité à Haïti entrave l'essor économique de l'île. (2008, 2 juillet). Le Monde International, pp.6.

Lonergan, S.; Gustavson, K. \& Carter, B. (2009). The Index of Human Insecurity. Recuperado

da: http://unpan1.un.org/intradoc/groups/public /documents.

Luchi, E. (2010). Between war and peace. Disasters, 4(34), 973-995. 
doi:10.1111/j.0361-3666.2010.01178.x

Médecins du Monde (2005). La prise en charge des victimes de violences. Actes du colloque. Port-au-Prince: les Éditions de l'Uramel.

Médecins Sans Frontières (2008). No cash, no care: How "user fees" endanger health.

An MSF briefing paper on financial barriers to healthcare. Médecins Sans

Frontières: Operational Center Brussels.

Médecins Sans Frontières (2010). Emergencies responses after the earthquake. Recuperado da www.msf.org

Melo King, A. (2010). Les différentes formes de violence à Léogâne et alentours:

enquête qualitative. MSF : Operational Center Geneva.

Minayo, M. C. S.; Hartz, Z.M.A. \& Buss, P. M. (2000). Qualidade de vida e saúde: um debate necessário. Ciência e Saúde Coletiva, 5(1), 7-18.

Montas-Dominique, M. (2011). If I don't shout. Em Farmer, P., Haiti after the

earthquake (pp. 259-272). New York: PublicAffairs.

MSF Briefing Paper (2008). The obstacles to safe delivery for vulnerable women in

Port-au-Prince. Médecins Sans Frontières Operational Center Amsterdam.

Neves, M. L. (2011). Elas levam a paz. Revista Marie Claire, edição de novembro, pp. 97 104.

Pan American Health Organization (1999). Humanitarian Assistance in Disaster

Situation. A guide of effective aid. Emergency Preparedness and Disaster Relief

Coordination Program. Washington, DC.

Pan American Health Organization (2011). Health response to the earthquake in Haiti: January 2010. Washington, D.C.

Pérez-Sales, P. (2003). Mental health in disasters: a psychosocial approach. Em Baubet,

T.; Le Roch, K.; Bitar, D. \& Moro, M.R. Soigner malgré tout (pp. 112-124). France:

Éditions La Pensée Sauvage.

Ponsar, F.; Ford, N.; Van Herp, M.; Mancini, S.; \& Bachyi, C. (2009). Mortality,

violence and access to care in two districts of Port-au-Prince, Haiti. Conflit and

Health. BioMed Central, 3(4), 1-6. doi:10.1186/1752-1505-3-4

Schwartz, T. T. (2011). First we need taxis. Em Farmer, P., Haiti after the earthquake

(pp. 330-343). New York: PublicAffairs.
Sutter, C. (2010). Haiti, país mal dito. Revista Mal-estar e Subjetividade, 10 (3), 931950.

Thomaz, O. R. (2010). O Terremoto no Haiti, o Mundo dos Brancos e o Lougawou. Novos Estudos (86), 23-39.

Trevors, J. T. \& Saier Jr. M.H. (2010). The crisis in Haiti, 2010: What's to be done?

Water Air Soil Pollut. 212:1-2. doi: 10.1007/s11270-010-0338-8

United States Institute of Peace. (2009). Haiti, a republic of NGOs? Recuperado da http://www.usip.org/events/haiti-republicngos.

WHOQOL Group (1995). The World Health Organization Quality of Life Assessment (WHOQOL): position paper from the World Health Organization. Social Science and Medicine 41(10):1.403-1.409. 
ANEXO 1.

Quadro resumo das condições de vida antes e depois do terremoto:

\begin{tabular}{|c|c|c|}
\hline $\begin{array}{l}\text { Aspectos relacionados à } \\
\text { qualidade de vida. }\end{array}$ & Antes do terremoto & Depois do terremoto \\
\hline Saúde e assistência médica. & $\begin{array}{l}\text { Doenças infecciosas relacionadas à } \\
\text { pobreza. Sistema deficitário de saúde } \\
\text { pública, compensado parcialmente } \\
\text { pela presença de organizações } \\
\text { internacionais e religiosas. Adesão a } \\
\text { práticas tradicionais de cura. }\end{array}$ & $\begin{array}{l}60 \% \text { das estruturas médicas } \\
\text { destruídas; insalubridade local } \\
\text { viabilizou a epidemia de cólera. }\end{array}$ \\
\hline $\begin{array}{c}\text { Educação e acesso à } \\
\text { informação. }\end{array}$ & $\begin{array}{c}\text { Ausência de educação pública } \\
\text { gratuita. } 47 \% \text { de analfabetismo; } \\
\text { Comunicação via rádio tem grande } \\
\text { importância comunitária; telefonia } \\
\text { celular é amplamente utilizada pela } \\
\text { população. }\end{array}$ & $\begin{array}{l}\text { Destruição de escolas e } \\
\text { universidades; construção de } \\
\text { instalações escolares e } \\
\text { universitárias provisórias. }\end{array}$ \\
\hline Renda e profissão. & $\begin{array}{l}\text { 80\% de desemprego. Trabalho } \\
\text { informal como fonte de renda; } \\
\text { emigração massiva e ajuda } \\
\text { financeira dos emigrantes para a } \\
\text { população residente. Violação de } \\
\text { direitos trabalhistas. }\end{array}$ & $\begin{array}{c}\text { Donativos convertidos em } \\
\text { produtos comerciáveis. Aumento } \\
\text { do desemprego. Implementação } \\
\text { de programas de renda mínima. } \\
\text { Aumento da inflação. }\end{array}$ \\
\hline Segurança. & $\begin{array}{l}\text { Insegurança urbana. Ausência de } \\
\text { iluminação pública nos bairros } \\
\text { pobres. Violência de gênero } \\
\text { endêmica (elevado índice de } \\
\text { estupros). }\end{array}$ & $\begin{array}{l}\text { Fuga de detentos. Aumento dos } \\
\text { casos de roubo e dos índices de } \\
\text { estupros; mulheres buscam } \\
\text { proteção nos acampamentos. }\end{array}$ \\
\hline $\begin{array}{l}\text { Meio ambiente, espaço } \\
\text { físico e moradia. }\end{array}$ & $\begin{array}{l}\text { Saneamento básico e coleta de lixo } \\
\text { deficiente; Insuficiência do sistema } \\
\text { de abastecimento de energia e água. }\end{array}$ & $\begin{array}{c}\text { Um milhão de pessoas } \\
\text { desabrigadas vivendo em } \\
\text { acampamentos. Incremento } \\
\text { significativo da insalubridade e } \\
\text { deterioração das condições } \\
\text { sanitárias. }\end{array}$ \\
\hline Lazer e tempo livre. & $\begin{array}{l}\text { O lazer é vivido coletivamente } \\
\text { através do futebol, da música e do } \\
\text { carnaval. }\end{array}$ & $\begin{array}{l}\text { A copa de } 2010 \text { foi grandemente } \\
\text { festejada bem como o carnaval } \\
\text { em } 2011 .\end{array}$ \\
\hline Família e rede social. & $\begin{array}{l}\text { Fragilização do laço familiar devido à } \\
\text { pobreza, baixa expectativa de vida e } \\
\text { sucessivos desastres naturais. } \\
\text { Vizinhos como fonte de apoio. }\end{array}$ & $\begin{array}{c}\text { Duplo efeito na rede social: } \\
\text { aumento da fragmentação } \\
\text { familiar e da solidariedade. } \\
\text { Abandono de mulheres e } \\
\text { crianças. }\end{array}$ \\
\hline $\begin{array}{l}\text { Perspectiva de vida e } \\
\text { satisfação com a própria } \\
\text { vida. }\end{array}$ & $\begin{array}{l}\text { Pessimismo em relação ao futuro; } \\
\text { desejo de abandonar o país. Elevado } \\
\text { índice de emigração. }\end{array}$ & $\begin{array}{l}\text { Sentimento de não } \\
\text { pertencimento ao entorno. } \\
\text { Incremento da diáspora. } \\
\text { Renovação do projeto de } \\
\text { reconstrução do país. }\end{array}$ \\
\hline $\begin{array}{c}\text { Espiritualidade e crenças } \\
\text { pessoais. }\end{array}$ & $\begin{array}{l}\text { Crenças religiosas como importante } \\
\text { fator de resistência frente às } \\
\text { adversidades da vida. Raízes } \\
\text { africanas preservadas nas praticas } \\
\text { vodus; religiosidade associada a } \\
\text { fatalismo. }\end{array}$ & $\begin{array}{l}\text { Reforço das práticas religiosas; } \\
\text { terremoto percebido como } \\
\text { castigo espiritual. }\end{array}$ \\
\hline
\end{tabular}

